\title{
Tema del traidor y del héroe: el juego de máscaras en un cuento de Borges
}

Recibido: $\quad 8$ de julio, 2020.

Aceptado: 12 de octubre, 2020.

Por: Lcda. Lis García-Arango ${ }^{1}$, Universidad de Concepción, Chile. ORCID: 0000-0001-6305-4530.

\section{Resumen}

En este artículo, se pretende analizar Tema del traidor y del héroe, de Jorge Luis Borges, a partir de la tesis sobre el cuento borgeano que plantea Ricardo Piglia. Se emplea una metodología que divide el análisis en diferentes historias que convergen en el texto: la Escénica y las Criminales. Se profundiza en los pormenores y se apropia de la intertextualidad con los cuentos: La muestra de la espada rota y La torre de la traición, de Gilbert Keith Chesterton, para reinterpretar el relato que, desde el comienzo, es una paradoja. ¿Se es traidor o se es héroe? Descifrar el enigma, bajo la lupa del crítico-lector como detective y del escritor como criminal, guía la investigación.

\section{Abstract}

\section{The Theme of the Traitor and the Hero: the mask game in a Borges story}

This article aims to analyze The Theme of the Traitor and Hero, by Jorge Luis Borges, based on the thesis on the Borgean story proposed by Ricardo Piglia. The methodology utilized divides the analysis into different narratives converging in the text: the Scenic and the Criminal. We delve into the subtleties and appropriate the intertextuality within the stories The Broken Sword Show and The Tower of Betrayal, by Gilbert Keith Chesterton, to reinterpret that the narrative is a paradox in itself. Are you a traitor or a hero? This study is guided by an effort to decipher the enigma, under the microscope of the critic-reader as a detective and the writer as a criminal.

1 La licenciada Lis García-Arango se graduó de la Licenciatura en Periodismo de la Universidad de La Habana, Cuba, y doctoranda en Literatura Latinoamericana de la Universidad de Concepción, Chile. Contacto: lisigaar@gmail.com.
Lis García-Arango. Tema del traidor y del héroe: el juego de máscaras en un cuento de Borges. Revista Comunicación. Año 41, volumen 29, número 2, julio-diciembre, 2020. Instituto Tecnológico de Costa Rica. ISSN: 0379-3974 / e-ISSN1659-3820.
PALABRAS CLAVE:

Jorge Luis Borges, Tema del traidor y del héroe, La torre de la traición, Chesterton, pormenores, principio de incertidumbre.

KEY WORDS:

Jorge Luis Borges, The Theme of the Traitor and Hero, Tower of Betrayal, Chesterton, details, principle of uncertainty. 
Cada hombre, potencialmente, abriga en su interior al héroe o al traidor. Se deviene en uno u otro según las circunstancias de la Historia. Historia que se construye, además, con la duplicidad de actos definitorios en la vida. Judas Iscariote, Marco Junior Bruto, Daniel O'Connell y Manuel Isidoro Suárez, ¿no podrían considerarse traidores y héroes a la vez? ¿Acaso el propio Borges no se debatió en atravesar tales límites? En Borges, "el héroe vive en la pura representación, sin nada personal, sin identidad. Héroe es el que se pliega al estereotipo, el que inventa una memoria artificial y una vida falsa" (Piglia, 2000, p. 52). En algunos de sus poemas autobiográficos como Borges y yo o El centinela-, se evidencia la idea de personalidad dividida. A Borges le preocupaba la división entre el hombre privado y el público, entre la memoria individual y la ajena: "A medida que trascurren los años, todo hombre está obligado a sobrellevar la creciente carga de su memoria. Dos me agobian, confundiéndose a veces: la mía y la del otro incomunicable" (Piglia, 2000, p. 50).

En Borges, el temor a perder la cultura tradicional y la identidad personal, basada en la memoria, lo sumergen en esa dicotomía. Por ello, tal vez, su escritura recurre a los pares opuestos de gauchos y bibliotecarios (en el cuento El sur), enciclopedias y cuchillos (símbolos de la civilización y la barbarie) y el referido Tema del traidor y del héroe, relato publicado en el libro Ficciones (1944).

Parodi (1999) advierte que a Borges lo atrae un rasgo formal del género policial: "la coexistencia (...) de dos historias, la del crimen y la de la investigación" (p. 81). Quizás debido a la marcada dualidad en el pensamiento de Borges, el autor argentino descubre en Poe, maestro del cuento policial, "dos argumentos; uno falso, que vagamente se indica, y otro, el auténtico, que se mantendrá secreto hasta el fin" (1996, p. 155). La estructura que Borges halla en Poe también la manejan Tzvetan Todorov y Josefina Ludmer.

Todorov asegura que la novela enigma contiene dos historias: la historia del crimen y la de la pesquisa. La historia del crimen se caracteriza por contar "lo que efectivamente pasó" (Todorov, 2003, p. 36) y la de la pesquisa por explicar "cómo el lector (o el narrador) tomó conciencia de ello" (p. 36). O sea, en la novela enigma se tratan dos historias, "una está ausente pero es real, la otra presente pero insignificante" (p. 37).
Por su parte, Ludmer (1977) plantea que la novela policial clásica cuenta dos historias: "la primera -el crimen- es lo que 'efectivamente ocurrió'; la segunda -la investigación- narra cómo el investigador 'se entera' de la primera; la única que se lee es la segunda historia, que comienza cuando la primera ha concluido" (p. 88). Esta línea estructural de los dos relatos que suponen "una elipsis, un blanco de no dicho para desencadenar la escritura" (p. 88), después la sigue Ricardo Piglia. Si bien, este cuento ha sido estudiado en numerosas ocasiones por la crítica (Brintrup, 1978; Dehennin, 1983; Varas, 1988; Pauls, 2004; Balderston, 2010), se considera igualmente oportuno, para los fines del análisis de Tema del traidor y del héroe en el presente artículo, seguir el modelo teórico de Piglia, acerca del carácter doble del cuento borgeano.

Piglia esboza una primera tesis en la que "un cuento siempre cuenta dos historias (...) El arte del cuentista consiste en saber cifrar la historia 2 en los intersticios de la historia 1 . Un relato visible esconde un relato secreto, narrado de un modo elíptico y fragmentario" (Piglia, 2000, p. 105-106). El hallazgo de las dos historias se traza bajo las categorías Historia Escénica e Historia Criminal, propuestas por Piglia para el estudio de La muerte y la brújula.

La historia siempre es infamante, que se liga mucho a la lectura de Borges del peronismo, que es una trama entre dos historias: una Historia Criminal y una Historia Escénica, y en un punto también se liga a su literatura, como en La muerte y la brújula, que es una Historia Criminal y una Historia Escénica que le montan a Lönnrot para Ilevarlo a su muerte (Piglia, 2013, 00:02:39).

De la Historia Criminal, en Tema del traidor y del héroe se desprenden historias reales de carácter histórico y autobiográfico, que poseen un correlato con las fuentes de inspiración de Jorge Luis Borges. La segunda tesis del autor de Respiración artificial, en la que se sostiene este artículo, plantea que "la historia secreta es la clave de la forma del cuento y de sus variantes" (Piglia, 2000, p. 108). De acuerdo con los planteamientos de Piglia, se entiende que la Historia Escénica se encuentra visible, y la Historia Criminal contiene hechos ocultos en el relato. Para hallar lo oculto en el texto "plagado de espacios en blanco, de intersticios que hay que rellenar" (Eco, 1979, p. 
76). Es decir, el lector deberá valerse del pormenor como llave a otras dimensiones en el relato; como cortina para traspasar a tantas historias como mundos posibles se cristalicen en el universo diegético.

En línea con lo anterior, el proceso de investigación, que falta y se debe realizar, no solo no está narrado, sino que anuncia la existencia de detalles y de zonas no reveladas en el cuento. Según Piglia (2000), "la teoría del iceberg de Hemingway es la primera síntesis de ese proceso de transformación: lo más importante nunca se cuenta. La historia secreta se construye con lo no dicho, con el sobreentendido y la alusión" (p. 108). Los pormenores pueden comportarse como pasadizos a otras historias que habitan el relato, pero que no se constatan en la Historia Escénica.

Cada una de las dos historias se cuenta de modo distinto. Trabajar con dos historias quiere decir trabajar con dos sistemas diferentes de causalidad. Los mismos acontecimientos entran simultáneamente en dos lógicas narrativas antagónicas. Los elementos esenciales de un cuento tienen doble función y son usados de manera diferente en cada una de las dos historias. Los puntos de cruce son el fundamento de la construcción (Piglia, 2000, p. 106).

El intertexto, entendido como la percepción, por el lector, entre una obra y otras que la han precedido o seguido contribuyen, junto al pormenor, a reinterpretar el relato que desde el comienzo es una paradoja. ¿Se es traidor o se es héroe? Descifrar las historias ocultas o Criminales en los intersticios de la historia visible, así como las causalidades de dichos relatos, constituye el objetivo del presente artículo.

\section{ACTO PRIMERO. HISTORIA ESCÉNICA}

En Tema del traidor y del héroe se aprecia cómo, desde el título, habitan dos contrarios en una misma frase (traidor/héroe), oxímoron que implica un reflejo inverso, una autorreferencialidad. El cuento comienza:

Bajo el notorio influjo de Chesterton (discurridor y exornador de elegantes misterios) y del consejero áulico Leibniz (que inventó la armonía preestablecida) he imaginado este argumento, que escribiré tal vez y que ya de algún modo me justifica, en las tardes inútiles. Faltan pormenores, rectificaciones, ajustes; hay zonas de la historia que no me fueron reveladas aún; hoy, 3 de enero de 1944, la vislumbro así (Borges, 1974, p. 496).

El argumento refleja, también, la conciliación de los polos aparentemente irreconciliables: Gilbert Keith Chesterton, el príncipe de las paradojas; y Gottried Wilhelm Leibniz, el rey de la razón. Por tanto, el principio de incertidumbre se siembra en los personajes principales: Ryan, bisnieto de Fergus Kilpatrick; Fergus Kilpatrick, bisabuelo del escritor, del biógrafo, del narrador y del detective Ryan; y James Alexander Nolan, traductor del idioma gaélico, articulista y el más antiguo de los compañeros de Fergus Kilpatrick.

El cuento se relata desde un país oprimido y tenaz: Polonia, Irlanda, la República de Venecia, o algún estado sudamericano o balcánico. Sin embargo, para 'comodidad narrativa', Borges lo sitúa en Irlanda a inicios del siglo XIX, fecha en la que el Estado procedía al proceso de unificación parlamentaria con Gran Bretaña y, consecuentemente, a la emancipación de los católicos por integrar el parlamento.

La narración se realiza desde el presente, en el siglo XX, al acercarse los 100 años de la ejecución del traidor y héroe. Exactamente, el 3 de enero de 1944, aunque los hechos ocurrieron al empezar el siglo XIX; por lo cual, se despliega en el tiempo del 2 al 6 de agosto de 1824. Asimismo, según el análisis narratológico que propone Genette (1989), contiene dos narradores. Uno heterodiegético (Borges), que no es personaje y comienza a narrar la historia en primera persona y luego en tercera. Y el otro, homodiegético (Ryan), quien no tiene voz propia en el texto. El narrador Borges, a partir de una metanarración, cuenta lo que le sucede a Ryan.

En este sentido, Ryan es el personaje-historiador que investiga sobre su bisabuelo Fergus Kilpatrick para escribir una biografía. Al parecerle enigmáticas las circunstancias de la muerte del familiar se afana y hurga en el pasado. Revela que la leyenda del héroe, urdida por James Alexander Nolan, fue apresurada y representada como una tragedia shakesperiana. El afán de Ryan por descifrar la causa de la muerte de Kilpatrick lo lleva a comprender que lo descifrado es falso y que detrás de esa historia hay otra trama secreta, que decide silenciar.

En Tema del traidor y del héroe la referida historia anteriormente es la visible, que se denominará como: 
Historia Escénica, pues todo el conflicto se desarroIla como una gran obra de teatro, un Festpiele como aquellas "vastas y errantes representaciones teatrales, que requieren miles de actores y que reiteran hechos históricos en las mismas ciudades y montañas donde ocurrieron" (Borges, 1974, p. 497). Escénica porque es la representación perceptible del argumento, la sucesión de hechos narrativos, de escenas. Y, también, porque la puesta escénica implica espacios oscuros, lugares detrás del telón, o fuera del escenario, donde, en última instancia, se urde la trama verdadera.

En esta línea, Piglia advierte que "un relato visible esconde un relato secreto, narrado de un modo elíptico y fragmentario (2000, p. 106) y Borges (1974) aporta la pista con el oxímoron "pública y secreta representación" (p. 498); pues, con ello advierte que, detrás de la visible, existen otras historias. Además, se perciben ciertas anomalías en el texto como "funerarias cortinas" (p. 498) y "populoso drama" (p. 498), cuyos significados simbolizan una escenificación de muerte teatral, tragedia o farsa.

Al respecto, las 'cortinas funerarias' permiten imaginar varias representaciones en el texto: la shakesperiana, tragedia de Julio César; la de Nolan, tragedia de Fergus Kilpatrick; la borgeana, tragedias históricas, humanas, de traidores y héroes; y la final, la tragedia histórica de la humanidad con el gran tema que es la muerte. Estas historias poseen un "carácter criminal" que el autor teje en los intersticios del texto, allí donde aparentemente no se notan. Es decir, Historias Criminales por furtivas, pero, también, por su inevitable manía de romper el pacto original de lectura, pues las claves para su comprensión, se encuentran, con frecuencia, fuera del texto mismo. Lo que Genette (1989) denomina como metatextualidad, que es la relación que "une un texto a otro texto que habla de él sin citarlo (convocarlo), e incluso, en el límite, sin nombrarlo" (p. 13).

En tal sentido, Borges parece inducir este procedimiento con la reiteración de determinados detalles. El símbolo de la Torre constituye el pormenor de larga resonancia en el relato. Desde el exergo, Borges plantea un fragmento del poema Nineteen hundred and nineteen, del poeta y dramaturgo irlandés William Butler Yeats, que se recoge en el libro The Tower. Se debe mencionar que Yeats compró en 1916 una torre normanda en Kiltartan Cross que se convirtió en el lugar de la escritura. Asimismo, la referencia más antigua se encuentra en la Biblia, en el pasaje de la Torre de Babel. Borges escribió el cuento La Biblioteca de Babel en el que acota que "al cabo de los siglos (...) los mismos volúmenes se repiten en el mismo desorden" (Borges, 1974, p. 471).

La intersección de dos detalles (el símbolo de la torre y "el influjo de Chesterton") conducen a que en el cuento exista una relación transtextual con La torre de la traición y La muestra de la espada rota, del autor británico, Gilbert Keith Chesterton. Vale aclarar que de acuerdo a Genette (1989): "la intertextualidad es [...] el mecanismo propio de la lectura literaria. En efecto, solo ella produce la significancia, mientras que la lectura lineal, común a los textos literarios y no literarios, no produce más que el sentido" (p. 11).

Por tanto, a través de la intertextualidad con las obras de Chesterton y Shakespeare, Borges evidencia el carácter paródico del cuento. Para Piglia (2001), "esa relación (...), con los textos de otro que el escritor usa en su escritura, esa relación con la literatura ya escrita que funciona como condición de producción está cruzada y determinada por las relaciones de propiedad" (p. 68). Sin embargo, en Tema del traidor y del héroe, "la huella intertextual es más bien como la alusión del orden de la figura puntual (del detalle) que de la obra considerada en su estructura de conjunto" (Genette, 1989, p. 11). Se arriba a esa conclusión a través del detalle visto como signo, como ente que encierra sentidos más allá de su valor léxico. Se debe recordar que "detrás de la cortina está el drama verdadero" (Chesterton, 1952, p. 1325).

\section{ACTO SEGUNDO. HISTORIA CRIMINAL I}

Piglia advierte que "el cuento es un relato que encierra un relato secreto" (2000, p. 107). Por tanto, el primer relato "secreto" o Historia Criminal que se narra simultáneamente a la historia visible, parece aludir al pasado familiar de Jorge Luis Borges. El carácter autobiográfico se determina por las concurrencias, demasiado precisas como para considerarlas azarosas, y porque Borges confiesa que "todo cuento mío, aunque sea fantástico, corresponde a una experiencia personal, sobre todo a una pasión personal" (Carrizo, 1979, 00:07:46).

Asimismo, las equivalencias entre el personaje ficticio Fergus Kilpatrick y el coronel Manuel Isidoro 
Suárez (bisabuelo de Borges) delinean el paralelismo entre ambos. Ryan es bisnieto del asesinado, del glorioso capitán de conspiradores Kilpatrick. Borges es bisnieto del coronel del ejército argentino, Manuel Isidoro Suárez, quien también fue un conspirador. Además, Borges (1976) le escribe el poema Coronel Suárez y, en vez de nombrarlo coronel, lo califica como un joven capitán: “(...) Detrás del simulacro te adivino, / oh joven capitán que fuiste el dueño / de esa batalla que torció el destino (...)" (p. 4)

Aunado a lo anterior, el relato del cuento es narrado el 3 de enero de 1944, dos años antes del primer centenario de la muerte de Isidoro Suárez, quien falleció en febrero de 1846 y, coincidentemente, con fecha cercana a cumplirse 100 años del asesinato de Fergus Kilpatrick. La historia transcurre en Irlanda, pero de igual manera pudo ocurrir en algún estado sudamericano como el Virreinato del Perú, en donde el coronel Suárez encabezó la caballería peruana y colombiana durante las Guerras de Independencia Hispanoamericana.

En el cuento Tema del traidor y del héroe, el 2 de agosto de 1824 se reunieron los conspiradores y el 6 de agosto de 1824 asesinan a Kilpatrick. En la historia familiar de Borges, en esa misma fecha (2 de agosto de 1824) fue el preludio de la Batalla de Junín, que terminó el 6 de agosto de 1824. Isidoro Suárez, quien la dirigió, fue arrestado y expulsado del Perú al ser acusado de intentar derrocar a Bolívar, junto con otros muchos oficiales argentinos.

En relación con el cuento, Kilpatrick "divisó y no pudo pisar la tierra prometida [...] pereció en la víspera de la rebelión victoriosa que había premeditado y soñado" (Borges, 1974, p. 496). Al respecto, Suárez tampoco pudo ver la independencia de la América Latina. Esta paridad, solo confirma un axioma de la poética borgeana: la circularidad del tiempo y de las situaciones; la comprensión, según uno de los puntales de la Weltanshauung, de que cualquier hombre es todo hombre.

\section{ACTO SEGUNDO. HISTORIA CRIMINAL II}

La segunda Historia Criminal identificada en el cuento, narra algunos paralelismos con personajes históricos. De acuerdo con Piglia (2000): "la variante fundamental que introdujo Borges en la historia del cuento consistió en hacer de la construcción cifrada de la historia 2 el tema del relato" (p. 110). Borges construye "perversamente una trama secreta con los materiales de una historia visible" (2000, p. 111). Piglia (2000) la resume de la siguiente manera:

Los patriotas irlandeses, rebeldes y románticos, son los destinatarios de una leyenda histórica urdida a toda prisa por Alexander Nolan, con el auxilio del azar y de Shakespeare, y esa ficción será descifrada muchos años después por Ryan, el asombrado e incrédulo historiador que reconstruye la duplicidad de la trama (p. 123).

En Tema del traidor y del héroe, la historia dos es la versión que hace Nolan. Y, como al destino le gustan las repeticiones, coloca a distintos hombres, en distintos tiempos y lugares, en situaciones semejantes: "Antes de ser Fergus Kilpatrick, Fergus Kilpatrick fue Julio César" (Borges, 1974, p. 497). Algunas coincidencias en ambas historias, conducen a establecer ciertas semejanzas. Julio César fue asesinado en el Teatro de Pompeyo, en Roma; Fergus Kilpatrick en un teatro en Dublín, Irlanda. Uno de los senadores, Cayo Casio Longino, junto a su cuñado Marco Junio Bruto ejecutaron el plan de asesinato; $y$, en contraste, el más antiguo compañero de Kilpatrick, Nolan, ejecutó el plan de asesinato.

De igual manera, Calpurnia, la mujer de Julio César, vio en sueños una torre abatida que le había decretado el Senado, luego, al encaminarse al lugar donde lo aguardaban los puñales, recibió un memorándum que no llegó a leer. Por su parte, los esbirros que examinaron el cadáver de Kilpatrick, hallaron una carta cerrada que le advertía el riesgo de concurrir al teatro y, en la víspera de su muerte, publicaron en todo el país el incendio de la torre circular de Kilgarvan.

Quizás el sueño de Calpurnia, la esposa de Julio César, reafirma la idea de que Borges ha imaginado este argumento trágico. Sin embargo, como "el arte de narrar se funda en la lectura equivocada de los signos" (Piglia, 2000, p. 123), Fergus Kilpatrick puede simbolizar al héroe universal que, acosado por sus inevitables luces y sombras, adviene en final trágico. Por un lado, luces que generan envidias y, por tanto, traidores que lo denostan. Por otro lado, sombras que, por sus propios defectos o errores, los condenan a la larga. 
Aunque la condición de Kilpatrick encuentra paralelo en disímiles personajes de la historia universal, ciertos detalles del cuento señalan especialmente a una figura histórica de Irlanda. Esto debido a que el Cementerio Glasnevin es el principal cementerio católico de Irlanda y tiene una torre circular y maciza con más de 150 pies de alto. Esta torre es un monumento funerario, en honor al libertador Daniel O'Connell, cuyo cuerpo yace enterrado debajo de ella, según su deseo moribundo, mientras su corazón fue enterrado en Roma. Nuevamente, la torre, que simboliza la inestabilidad de la vida y la condición pasajera y no perenne del hombre, conduce a esta relación.

O’Connell, en cierto sentido, ejerce correlación con Kilpatrick. Puede considerarse un héroe porque fue un político influyente de su tiempo que luchó por las reivindicaciones irlandesas frente a Inglaterra (logró la emancipación y la abolición de las trabas legales para que los católicos desempeñaran cargos públicos en el Reino Unido). Además, podría calificarse como traidor, porque se opuso a todo levantamiento armado y rechazó los métodos violentos empleados durante la Revolución Irlandesa que hicieron perder a Irlanda su Parlamento autónomo (Ley de Unión de 1800).

Otra similitud entre la leyenda de un conspirador irlandés (Fergus Kilpatrick) y uno inglés (Arthur Saint Claire), inducen a suponer una relación intertextual con el cuento La muestra de la espada rota, de Chesterton. En este cuento, el general inglés St. Claire es ejecutado por sus propios hombres cuando descubren que asesinó a un compañero, pero callan la traición y dicen que murió peleando como un héroe, pues no quieren ensuciar la historia guerrera del imperio.

En el cuento de Chesterton, hay dos historias: la visible o escénica en la que se plantea que St. Claire fue un héroe; y la secreta o criminal, en donde fue un traidor, igual que en el texto de Borges. También, en ambos cuentos hay un investigador (el padre Brown, en Chesterton y Ryan, en Borges) que sigue las pistas y descubre la historia secreta. Nolan organiza el asesinato para que Kilpatrick muera como héroe y estalle la rebelión, tal como lo hacen los soldados del general inglés. Antes de ser Fergus Kilpatrick, este pudo ser Arthur Saint Claire.
Aunado a lo anterior, el símbolo de la torre puede representar al camposanto de la iglesia donde se encuentra la sepultura del general St. Claire, en cuya lapida, tallada en letras negras, se dedican las siguientes palabras: "héroe y mártir, que siempre venció a sus/ enemigos y siempre supo/ perdonarlos, y al fin murió/por la traición a manos de ellos" (Chesterton, 2003, p. 266). En ese cementerio, con la efigie de Claire - quien sostiene a la derecha una espada con la punta rota y a la izquierda una Biblia- se desencadena el desciframiento del misterio de la historia contradictoria de un traidor convertido en héroe, a partir de las confesiones del padre Brown a Flambeau. El sacerdote le advierte a su discípulo que Olivier y St. Claire eran héroes, tal como lo eran Kilpatrick y Nolan, pero, lamentablemente, en ocasiones los venerados héroes suelen comportarse tímida o traicioneramente. Es decir, la actitud de un día puede transformar el curso de los hechos.

Asimismo, La muestra de la espada rota contiene analogías que permiten validar la intertextualidad. En el relato de Chesterton, el capitán Keith, el comprometido y luego esposo de su hija, escribió la autobiografía: Un oficial inglés en Birmania y en el Brasil, en donde alude al misterioso fin de St. Claire. Aclara que "ni St. Claire fue tan necio ni Oliver tan bárbaro como parece" (Chesterton, 2003, p. 271). Además, los documentos que custodiaba Espada, apodado el Buitre, que habían sido de un soldado inglés, contribuyen a que el padre Brown, al igual que Ryan, descubran la verdad.

St. Claire al parecer necesitaba mucho dinero, uno de los motivos era para dotar de riqueza a la hija que amaba. Por ello, se especula en el texto, que fue y le dio el "soplo" a las tropas brasileñas y los enemigos de Inglaterra lo colmaron de oro. El incidente lo sospechó Murray, el Mayor de Ulster, quien le dijo que renunciara al mando para ser debidamente procesado. La reacción de St. Claire fue desenvainar e hincar la hoja de la espada en el Mayor. Al marcharse, la punta de la espada se encontraba rota, un pedazo quedó clavada en el pecho de su víctima.

Ese paralelismo y otros "suponen una secreta forma del tiempo, un dibujo de líneas que se repiten" (Borges, 1974, p. 497). En este sentido, "el cuento se construye para hacer aparecer artificialmente algo que estaba oculto. Reproduce la búsqueda siempre 
renovada de una experiencia única que nos permita ver, bajo la superficie opaca de la vida, una verdad secreta" (Piglia, 2000, p. 111). En Tema del traidor y del héroe y La muestra de la espada rota, la 'verdad secreta' refleja que tanto Kilpatrick como St. Claire fueron asesinados por sus propios hombres. A St. Claire, la mano que le puso el nudo al cuello en la horca, fue la misma que le puso el anillo a su hija en el dedo. En otras palabras, los mismos que antes los adoraron, ahora los asesinan.

\section{ACTO SEGUNDO: HISTORIA CRIMINAL III}

Afirma Piglia (2000) que Borges cierra sus historias "siempre con ambigüedad" (p. 115), el fin es siempre "involuntario o parece involuntario pero está premeditado y es fatal" (p.115). Por tanto, existen notables hechos que permiten reinterpretar el cuento borgeano y que alteran la significación. El relato de Borges, dice Piglia (2000), se dirige a "un interlocutor perplejo que va siendo perversamente engañado y que termina perdido en una red de hechos inciertos y de palabras ciegas. Su confusión decide la lógica íntima de la ficción" (p. 123).

En línea con lo anterior, La muestra de la espada rota permite continuar tejiendo la red de "hechos inciertos". Esto debido a que se conjetura que St. Claire fue quien delató los planes de su ejército con el bando enemigo para ganar plata y, para no ser descubierto, mató a quien sospechaba el delito. En este texto, se conoce la causa de la traición, pero en Tema del traidor y del héroe nunca se dice que hizo Kilpatrick para condenarle.

Asimismo, St. Claire, cuando Murray lo intercede y le pide ser ajusticiado, no acepta su condena y actúa violentamente al penetrarle la espada hasta matarlo. En el caso de Kilpatrick, ocurre lo contrario. Siempre es referido como un héroe: "el joven, el heroico, el bello, el asesinado, glorioso capitán" (Borges, 1974, p. 496). También, cuando firmó su propia sentencia e imploró que su castigo no perjudicara a la patria, valida la virtud del héroe. Kilpatrick era idolatrado en Irlanda; por eso, no quería comprometer la rebelión. Conoce su destino, pero prefiere callar y morir para no atrasar la rebelión. Igualmente, desde cierto ángulo, el héroe parece víctima de una conspiración interna, de un complot de Nolan para eliminarlo y asumir el mando.
Debido a la enigmática muerte de su bisabuelo, Ryan indaga que, en 1814, James Alexander Nolan había traducido al gaélico los principales dramas de Shakespeare; entre ellos, Julio César. En el universo diegético del cuento de Borges, Nolan es el único que ha leído y posee conocimiento de las obras shakesperianas. Además, Nolan escribió un artículo sobre los Festpiele de Suiza. Asimismo, otro manuscrito inédito le revela a Ryan que, pocos días antes del fin, "Kilpatrick, presidiendo el último cónclave, había firmado la sentencia de muerte de un traidor, cuyo nombre ha sido borrado. Esta sentencia no coincide con los piadosos hábitos de Kilpatrick" (Borges, 1974, p. 497).

Nolan, al parecer, se inspiró en la obra de Shakespeare para urdir su plan y, por tanto, en la historia romana, para repetirla en la Irlanda de 1824. Por tanto, se constata nuevamente la parodia a la historia que realiza Borges y la intertextualidad manifiesta con Chesterton. Tal y como Borges (1974) afirma en Tema del traidor y del héroe, "que la historia hubiera copiado la historia ya era suficientemente pasmoso; que la historia copie a la literatura es inconcebible [...]" (p. 497). Ryan, una vez que descubre la causa del asesinato del héroe de la independencia irlandesa, decide silenciarla porque comprende que él también forma parte de la trama de Nolan, quien mueve los hilos de la historia como marionetas a su antojo. Entonces, Ryan comprende que "hay otra trama silenciosa y secreta, que estaba destinada" (Piglia, 2000, p. 123).

Si Kilpatrick fue Julio César, ¿quién fue Nolan? Podría suponerse que Nolan fue Cayo Casio Longino o Marco Junio Bruto, todos ejecutores del plan de asesinato. Los indicios sobre el complot que está trazando el destino de Kilpatrick, como el mismo escritor traza el destino de sus personajes, comienza desde que "la historia copia a la literatura" (Borges, 1974, p. 497). Es decir, desde que se elabora el extraño proyecto ejecutorio, inspirado en Shakespeare.

Nolan preparó toda la conspiración contra Kilpatrick, al igual que Bruto lo hizo con César. Algunos hechos que permiten verificar que Nolan es un complotado se advierten cuando, luego de que Kilpatrick le encomendara el descubrimiento del traidor, ipso facto y sin tiempo para investigar, ejecutó su tarea: anunció que el traidor era Kilpatrick. Esto demuestra que la acción era premeditada. Borges, al igual que 
Dupin y otros detectives "trabaja con el complot, la sospecha, la doble vida, la conspiración, el secreto" (Piglia, 2001, p. 15).

Sin embargo, donde mejor se evidencia la tesis del complot de Nolan, es a través de la intertextualidad con el cuento La torre de la traición, de Chesterton. Pues, se reafirma que unas minorías trazan el destino de los demás: "La concepción conspirativa de la historia tiene la estructura de un melodrama: una fuerza perversa, una maquinación oculta explica los acontecimientos" (Piglia, 2001, p. 36). O sea, en quien menos se podría pensar o dudar, urde la traición en el relato de Chesterton:

¿Cómo podía un mujik de Moscú asesinarlo en un teatro de Munich? (al primer ministro alemán que había reducido a Rusia a la pobreza). Lo asesinó un hombre que fue allí porque era un buen bailarín ruso y que escapó de allí porque era un buen acróbata ruso. Es decir; el odiado estadista no fue asesinado por todos los rusos que podían haber querido matarle, sino por el único ruso que pudo matarle? (Chesterton, 1952, p. 1343).

Sin dudas, la intertextualidad con el cuento de Chesterton alerta que Nolan es el único que podía haber matado a Kilpatrick. En La torre de la traición, el abad "hubiera muerto antes de hacer traición a las santas piedras" (Chesterton, 1952, p. 1330), lo que es totalmente falso, pues este es el asesino, en complot con el Doctor Amiel, propietario de un castillo con varias torres. Borges se vale de este relato que se ubica en las fronteras húngaras, que se pierden en los Balcanes, para "expresar la verdad como una paradoja" (1952, p. 1323). Al respecto, Piglia (2000) advierte que al final surge una realidad desconocida que "hace ver un sentido secreto que estaba cifrado y como ausente en la sucesión clara de los hechos" (p. 124). Kilpatrick muere para que Ryan descubra la verdad del misterioso asesinato. Stephen también muere porque "podría ser mi deber volver otra vez al mundo, y en este caso sería mi deber morir" (1952, p.1325) y para que Bertram Drake descifre "la serie de extraños sucesos...que no solo era(n) una tragedia, sino un enigma" (1952, p. 1322).

En la narración de Chesterton, el inocente es quien muere desde la torre de la traición. Mientras en las escenas de Shakespeare y de Borges, se desconoce al matador. Si se descompone el nombre Fergus Kil- patrick y se apela a la teoría de Borges propuesta en el ensayo Los cuatro ciclos (el de la Guerra, el de un Viaje sin retorno, el de una Búsqueda y la de la Crucifixión de un Dios), Tema del traidor y del héroe se ajusta a la historia de la Crucifixión de un Dios. Entonces, Fergus significa selecto, Kil se asocia con kill (matar en inglés, idioma que Borges maneja a la perfección) y Patrick es el Santo patrón de Irlanda, predicador del evangelio cristiano y máxima figura católica de Irlanda. Por tanto, Kilpatrick representa a un Dios que se inmola. Kilpatrick murió con la verdad en el corazón, como el anacoreta Stephen. Guardó la verdad en el pecho, aunque la verdad le causó la muerte: "Es la raíz de toda religión que cualquiera puede ser casi cualquier cosa si se le antoja. Los cínicos yerran, no en decir que los héroes pueden ser cobardes, sino en no ver que los héroes pueden ser héroes" (Chesterton, 1952, p. 1333).

\section{CONCLUSIONES}

La heroicidad y la traición se desplazan por senderos bifurcados. La línea divisoria se traza por las encrucijadas del destino. El contagio entre estos polos se descontamina por la posición molar de unos sobre otros. La porosidad entre las condiciones se funde o determina por la selección mediada por los contextos. Por tal motivo, en el análisis de Tema del traidor y del héroe, se intenta, en un primer momento, reflejar la paradoja de las categorías irreconciliables $y$, a la vez, simétricas que pueden converger en un mismo personaje: traidor o héroe. Kilpatrick pudo ser un traidor que devino en héroe y Nolan un héroe que devino en traidor. También, el cuento La muestra de la espada rota narra la historia de un héroe que se convierte en traidor y que, al morir, mantiene la condición heroica.

En un segundo momento, se pretende descubrir los relatos secretos en el acto de lectura a partir del modelo teórico de Ricardo Piglia sobre las dos historias en los cuentos de Borges. En este artículo, se presentan las Historias Escénica y Criminales (I, II, III) detectadas tras el análisis. Las historias ocultas o Criminales establecen una conexión directa con la metafísica y la ciencia de la microscopía. En tal sentido, la revelación de estas historias se conoce a través de los detalles o pormenores. 
En el Acto I: Historia Escénica, se muestra el relato visible en donde Ryan decide silenciar el descubrimiento sobre la muerte de su bisabuelo Fergus Kilpatrick. La causalidad consiste en el afán de Ryan por descifrar el enigma de la muerte de Kilpatrick. En el Acto Segundo Historia Criminal I, se narra el primer relato "secreto" y, simultáneamente a la historia visible, se evidencia la alegoría al paralelismo entre la historia de Kilpatrick y Manuel Isidoro Suárez, bisabuelo de Borges. En la Historia Criminal II, se explica cómo Fergus Kilpatrick simboliza al héroe universal que, acosado por sus inevitables luces y sombras, adviene en final trágico. Por último, en la Historia Criminal III, se desarrolla el argumento de que Fergus Kilpatrick, víctima de un complot orquestado por Nolan, decide asumir la condena y, para exonerarse, Nolan inculpa a Kilpatrick de traición, quien asume la condena para no frustrar la rebelión.

Pero, ¿quién puede legitimar la verdad de las Historias Escénica y Criminales? ¿Acaso el crítico? El principio de incertidumbre constatable durante todo el relato depende, en cierta medida, de lo que el crítico descifre en el texto, de la habilidad de ocultamiento del narrador y de la sutileza del acto; luego de que el escritor, como buen criminal, borre las pistas y huellas que lo delatan. En resumen, el crítico-lector intenta hallar la "verdad" y "borrar la incertidumbre que define a la ficción" (Piglia, 2001, p. 13).

\section{REFERENCIAS BIBLIOGRÁFICAS}

Balderston, D. (2010). "Digamos Irlanda, digamos 1824»: para repensar la historia en Borges". Innumerables relaciones: cómo leer con Borges. Primera edición. Santa Fe: Ediciones UNL.

Balderston, D. (1990). Historical Situations in Borges. MLN, 105(2), 331-350. doi:10.2307/2905297

Balderston, D. (2011). The rag-and-bone shop: on Borges, Yeats and Ireland. Variaciones Borges, (32), 41-58.

Balderston, D. (2017). Borges en el mundo, el mundo en Borges. Revista Chilena De Literatura, (96), 55-66.

Borges, J. L. (2016). El aprendizaje del escritor. Editorial Lumen.

Borges, J. L. (1974). Obras completas (1923-1972). Buenos Aires: Emecé Editores.

Borges, J. L. (1996). Obras Completas. Volumen IV (19751985). Barcelona: Emecé Editores.
Borges, J. L. (1976). La Moneda de Hierro. Buenos Aires: Emecé Editores.

Brintrup, L. (1978). Borges/Bremond: análisis estructural del Tema del traidor y del héroe. Revista Chilena de Literatura, 12, 91-103

Carrizo, A. [Raridades]. (1979, 13 de diciembre). Entrevista a Jorge Luis Borges por Antonio Carrizo [Video de YouTube]. Recuperado de https://www.youtube.com/ watch?v=dUZJGhPqspQ

Chesterton, G. K. (1952). Obras completas. Tomo II. Editorial: Janés.

Chesterton, G. K. (2003). El candor del padre Brown. Ediciones del Sur.

Dehennin, E. (1983). Tema del traidor y del héroe: un modelo narratológico para desarmar. Presentado en el Congreso de la Asociación Internacional de Hispanistas, Actas del octavo, Rhode Island, Brown University. Recuperado de http://www.cervantesvirtual.com/obra/ tema-del-traidor-y-del-heroe-un-modelo-narratologicopara-desarmar/

Eco, U. (1979). Lector in fábula. La cooperación interpretativa en el texto narrativo. España: Editorial Lumen.

Genette, G. (1989). Palimsestos. La literatura en segundo grado. España: Editorial TAURUS.

Ludmer, J. (1977). Onetti. Los procesos de construcción del relato. Buenos Aires: Sudamericana.

Parodi, C. (1999). Borges y la subversión del modelo policial. En R. Franco (Ed.), Borges: Desesperaciones aparentes y consuelos secretos (pp. 77-98). México, D.F.: El Colegio de México. doi:10.2307/j.ctvhn07xs.7

Pauls, A. (2004). El factor Borges. Barcelona: Editorial Anagrama.

Piglia, R. (2000). Formas breves. Barcelona: Editorial Anagrama.

Piglia, R. (2001). Crítica y ficción. Barcelona: Editorial Anagrama.

Piglia, R. [Televisión Pública]. (2013, 30 de setiembre). Borges, por Piglia - Clase 4 - 28-09-13 (3 de 4) [Video de YouTube]. Recuperado de: https://www.youtube.com/ watch? v=OOCsvnDaK_o.

Todorov, T. (2003). Tipología de la novela policial. En D. Link (Comp.), El juego de los cautos Literatura policial: de Edgar A. Poe a P. D. James (pp. 34-39). Buenos Aires: Editora La marca.

Varas, P. (1988). Intertextualidad en el cuento Tema del traidor y del héroe de Jorge Luis Borges. Texto Crítico, (39), 90-97. 